\title{
A meta-analysis and systematic review on subtypes of gastric intestinal metaplasia and neoplasia risk
}

Ning Wei ${ }^{1,2+}$, Mengyue Zhou ${ }^{1,2+} \odot$, Siyu Lei ${ }^{1,2}$, Zhiheng Zhong ${ }^{1,2}$ and Ruihua Shi ${ }^{1,2^{*}}$

\begin{abstract}
Background: Gastric intestinal metaplasia (GIM) is a significant risk factor for gastric cancer. Risk of gastric cancer/ dysplasia between complete intestinal metaplasia (CIM) and incomplete intestinal metaplasia (IIM) was controversial. Our study aimed to pool relative risk (RR) of cancer/dysplasia of IIM compared with CIM in GIM patients.

Methods: PubMed, EMBASE, Cochrane Library and Web of Science were searched for studies concerning cancer/dysplasia in GIM patients. Random-effects or fixed-effects model was utilized for pooling RR. Sensitivity and publication bias analyses were conducted. Stability of results would be evaluated in case of publication bias.

Results: 12 studies were included. Compared with CIM, pooled RR of cancer/dysplasia in IIM patients was 4.48 (95\% $\mathrm{Cl} 2.50-8.03$ ), and the RR was 4.96 (95\% Cl 2.72-9.04) for cancer, and 4.82 (95\% Cl 1.45-16.0) for dysplasia. The pooled RR for cancer/dysplasia in type III IM was 6.27 (95\% Cl 1.89-20.77) compared with type II + I IM, while it was 5.55 (95\% Cl 2.07-14.92) compared with type II IM. Pooled RR between type II IM and type I IM was 1.62 (95\% Cl 1.16-2.27). Subgroup analyses showed that IIM was associated with a higher risk of gastric cancer/dysplasia in Western population (pooled RR=4.65 95\% Cl 2.30-9.42), but not in East Asian population (pooled RR=4.01 95\% Cl 0.82-19.61).
\end{abstract}

Conclusions: IIM was related to a higher risk of cancer/dysplasia compared with CIM. Risk of developing cancer/dysplasia from type I, II, and III intestinal metaplasia increased gradually.

Keywords: Subtypes, Intestinal metaplasia, Gastric cancer, Dysplasia, Meta-analysis

\section{Background}

According to Correa's gastric cancer model, gastric intestinal metaplasia (GIM) is a significant risk factor for gastric cancer [1]. GIM was found in $25.3 \%$ of patients with dyspepsia and $100 \%$ of patients with intestinal-type gastric cancer [2]. Around 1 in every 39 patients with GIM would progress into gastric cancer within 20 years [3], which was similar to the result of De Vries et al. [4] an annual incidence of gastric cancer of $0.25 \%$. During

\footnotetext{
*Correspondence: ruihuashi@126.com

${ }^{\dagger}$ Ning Wei and Mengyue Zhou contributed equally to this study

${ }^{2}$ Department of Gastroenterology, Southeast University Affiliated Zhongda Hospital, No. 87 Dingjiaqiao, Nanjing 210009, China

Full list of author information is available at the end of the article
}

patients undergoing routine endoscopy, the prevalence of GIM ranged from 13.8 to $19 \%$ in Europe [5, 6], 37\% in Japan and 29\% in China [7], which necessitates the further identification of high-risk patients among GIM patients. Some markers, such as score of operative link for gastric intestinal metaplasia assessment (OLGIM) [8], endoscopic grading of gastric intestinal metaplasia (EGGIM) $[9,10]$ and family history of gastric cancer [11], have been recommended for identifying those high-risk patients. There are three subtypes of GIM, with type I termed "complete IM" (CIM) and types II and III named "incomplete IM" (IIM). In some studies [12-14], patients with IIM were at higher risk for gastric cancer than those with CIM, which was inconsistent with other studies [15-20]. Therefore, additional studies are 
required before IIM can be used to distinguish patients at higher risk for gastric cancer [10]. In a subgroup analysis of the meta-analysis conducted by Shao et al. [1], IIM (pooled OR $=59.48,95 \%$ CI 4.33-20.78) was associated with a higher risk of gastric cancer than CIM (pooled $\mathrm{OR}=51.55,95 \%$ CI 0.91-2.65) in patients with GIM. But the risk of malignant transformation of IIM compared with CIM was not clarified. In view of these controversies, our study aimed to pool the relative risk (RR) of cancer/dysplasia of IIM compared with CIM in patients with GIM. We also compared the predictive ability among 3 subtypes of intestinal metaplasia.

\section{Methods}

\section{Search strategy}

A literature search in online medical databases including PubMed, EMBASE, Cochrane Library, and Web of Science was performed by two authors (M.Z. and W.N.) independently to identify relevant studies (published until March 2020) on the incidence rate of cancer/dysplasia in patients with specific subtypes of GIM. Besides, we also checked the reference lists of relevant review articles and included studies to find any other eligible articles. Search strategy was based on the following terms and keywords: ("IM" OR "intestinal metaplasia") AND ((("gastric" OR "stomach") AND (("cancer" OR "adenocarcinoma" OR "tumor" OR "carcinoma" OR "neoplasm”)) OR "dysplasia") AND ("subtype" OR "variant" OR "type I")).

\section{Inclusion and exclusion criteria}

Two authors (M.Z. and N.W.) independently screened articles that met the following inclusion criteria: (1) compared with CIM, odds ratio, relative risk or hazard ratio with their 95\% confidence interval (95\% CI) (or data to calculate them) of cancer/dysplasia were reported in patients with IIM (2) there were cases of cancer/dysplasia in the cohort study. In vitro or animal studies, seminar reports, case reports, case series, and duplicate publications were excluded.

\section{Data extraction}

Two reviewers (M.Z. and N.W.) independently conducted the data extraction procedure, and a third investigator (Y.L.) would resolve the inconsistency. Information including first author, publication year, study design, country of origin, sample size, duration of follow-up in cohort studies, risk estimates and adjusted factors, was extracted from each study.

\section{Quality assessment}

The quality of each included study was assessed by 2 reviewers (M.Z. and N.W.) according to the
Newcastle-Ottawa Scale (NOS) [21]. Article with total NOS score $<7$ were rated as low-quality, and $>6$ as highquality studies.

\section{Statistical analysis}

Relative result was pooled using either a random or fixed effects model on the basis of the result of heterogeneity analysis. $\mathrm{Q}$ and $\mathrm{I}^{2}$ statistics was used to evaluate the heterogeneity of our study, and $\mathrm{p}<0.05$ or $\mathrm{I}^{2}>50 \%$ indicated significant heterogeneity [22]. The primary aim of our meta-analysis was to investigate RR of cancer/dysplasia in IIM when compared with CIM. We also conducted subgroup and sensitivity analyses to explore source of heterogeneity and to evaluate the pooled RR in 3 different subtypes of GIM (type III vs. II; type II vs. I; type III vs II $+\mathrm{I}$ ), study design (cohort or case-control), district (East Asia or the West). Publication bias risk was evaluated by Egger's test and funnel chart. If there was publication bias, we would evaluate the stability of the results by trim and fill method [23, 24]. All analyses were performed by the Stata software (V.15.0; Stata Corp, College Station, TX), and $\mathrm{p}$ values $<0.05$ was considered significant. For the low morbidity of cancer/dysplasia, odds ratio and hazard ratio yield similar estimates of rate ratio in practice $[25,26]$.

\section{Results}

Characteristics of the included studies

A total of 919 articles was collected initially from PubMed, Embase, Web of Science and Cochrane Library, of which 33 were potentially relevant reports for further review. And then 21 studies were excluded further for the following reasons: didn't involve the risk of cancer/ dysplasia of specific subtype of GIM $(n=13)$; lack of data $(n=5)$; not original articles $(n=3)$. As shown in Fig. 1, 12 studies were finally included in this meta-analysis.

Table 1 showed the characteristics of the included studies. 11 studies involved the cancer risk of IIM, 4 studies involved the dysplasia risk. Most of the included studies were conducted in the West $(n=8), 3$ in East Asia, and one in Colombia [27]. During the included studies, 7 were cohort studies, while 5 were case-control studies. Each study included men and women. Most biopsy protocols included both the antrum and corpus. The main method to distinguish subtypes was using Alcian blue $\mathrm{pH}$ 2.5/periodic acid Schiff (AB-PAS) and high iron-diamine/ Alcian blue $\mathrm{pH} 2.5$ (HID/AB).

\section{Gastric cancer/dysplasia risk among the patients with incomplete intestinal metaplasia}

Compared with CIM, the pooled RR of cancer/dysplasia risk among the patients with IIM was 4.48 (95\% CI 2.50$8.03)$ with significant heterogeneity $\left(\mathrm{I}^{2}=76.9 \%, \mathrm{p}<0.001\right)$ 


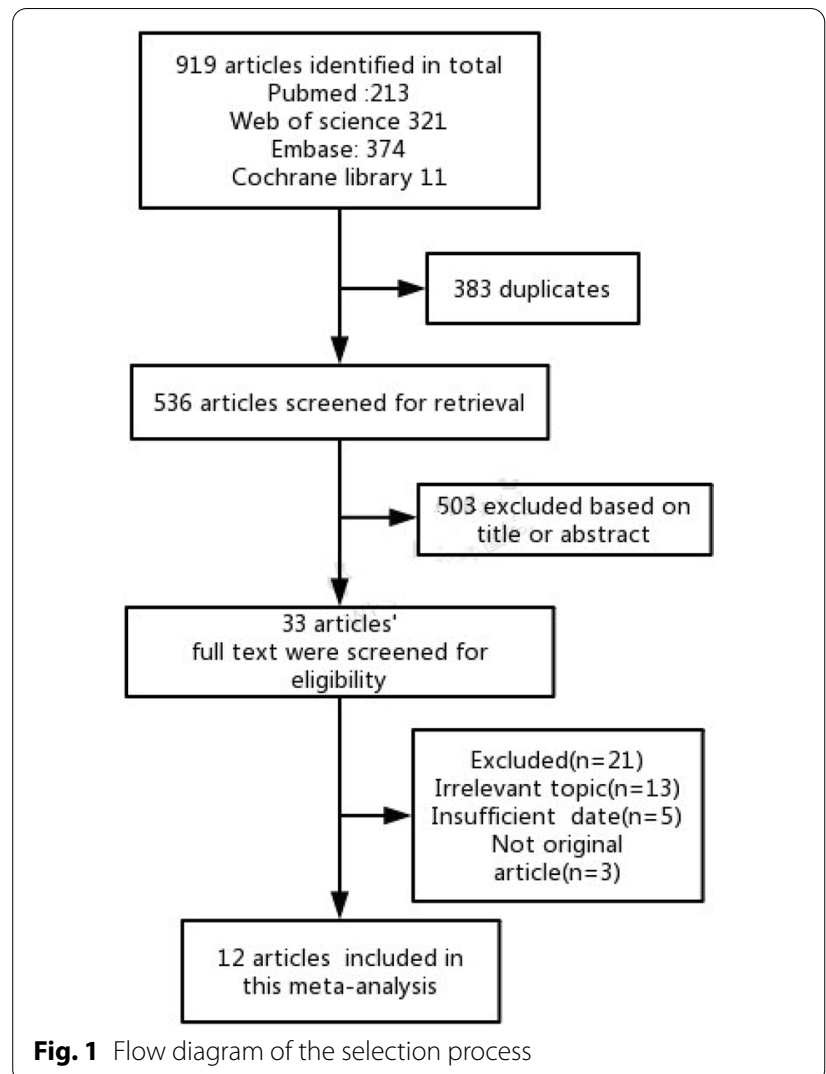

(Fig. 2a), indicating a higher cancer/dysplasia risk among the patients with IIM. Besides, for gastric cancer, compared with CIM, the pooled RR for patients with IIM was 4.96 (95\% CI 2.72-9.04) (Fig. 2b). And incomplete IM was also associated with a significantly higher risk of dysplasia (pooled RR $=4.82,95 \%$ CI 1.45-16.0) (Fig. 2c).

\section{Subgroup and sensitivity analyses}

When it came to type III vs. II \& I, type III vs. II, and type II vs. I, the RR of cancer/dysplasia were also performed respectively. The pooled RR for type III was 6.27 (95\% CI 1.89-20.77) when compared with type II $+\mathrm{I}$, while it was 5.55 (95\% CI 2.07-14.92) when compared with only type II. The initial pooled RR between type II and I was 1.30 (95\% CI 0.97-1.74) (Additional file 1: Figure S3), however 1 study [28] was excluded after sensitivity analysis (Additional file 1: Figure S4, Table S4), and the pooled RR of the remaining 6 studies was 1.62 (95\% CI 1.16-2.27) (Fig. 3). Subgroup analyses were also performed according to study design and country of origin, as shown in Table 2. IIM was associated with a higher gastric cancer/dysplasia risk both in cohort studies (pooled $\mathrm{RR}=5.05$, 95\% CI 2.07-14.92) and case-control studies (pooled RR $=3.15$ 95\% CI 1.48-6.73). Moreover, pooled RR for the association between IIM and gastric cancer/dysplasia risk was significant in western countries (pooled $\mathrm{RR}=4.6595 \% \mathrm{CI}$ 2.30-9.42), rather than East Asia (pooled $R R=4.0195 \%$ CI 0.82-19.61).

Besides the result of type II vs. I IM, which was discussed above, the stability of the outcome was also confirmed by the sensitivity analysis (Additional file 1: Figure S1, Table S1).

\section{Publication bias}

For the risk of cancer/dysplasia of IIM versus CIM, funnel plot and Egger's test suggested that publication bias may exist ( $P$ value of Egger's test $=0.002$ ) (Additional file 1: Table S2, Figure S2). The results of trim and fill method showed that the conclusion was still significant after adding 5 potential missing studies [pooled $R R=2.664$ ( $95 \%$ CI 1.546-4.591)] (Additional file 1: Table S3). Besides, the funnel plots showed that asymmetric studies were mostly those with small samples, and those with larger samples were basically symmetric, which further verified the reliability of the conclusion. Therefore, we can still conclude that IIM meant a higher risk of cancer/dysplasia than CIM.

\section{Discussion}

At present, the predictive value of IIM for cancer/dysplasia is still controversial. Some studies still question the predictive value of GIM subtypes for neoplasia [15-18]. Therefore, the British Society of Gastroenterology (BSG) and Management of epithelial precancerous conditions and lesions in the stomach (MAPS II) $[10,36]$ both suggested that more relevant evidence was needed before further clinical application. Our study was the first metaanalysis on the cancer/dysplasia risk among patients with IIM compared with CIM. We found that among patients with GIM, patients with IIM had a significantly higher risk of developing cancer (pooled RR $=4.9695 \%$ CI 2.729.04), dysplasia (pooled $R R=4.8295 \%$ CI 1.45-16.0), and cancer/dysplasia (pooled $\mathrm{RR}=4.48$ 95\% CI 2.50-8.03) than those with CIM. Thus, the emergence of IIM had a certain predictive value of the occurrence of cancer/dysplasia. A study performed by Craanen et al. [37] found that type III IM was strongly associated with intestinaltype carcinoma but not with benign lesions $(\mathrm{P}<0.01)$ or diffuse-type carcinoma. However, we did not pool the risk for intestinal-type cancer and diffuse-type gastric cancer respectively for lack of relative data, which needed further research.

In both study types included in the current study (cohort and case-control studies), patients had IIM were at higher risk of developing cancer/dysplasia. However, as for the population, the hypothesis that IIM had a higher risk of cancer/dysplasia than CIM was statistically confirmed only in the western population 


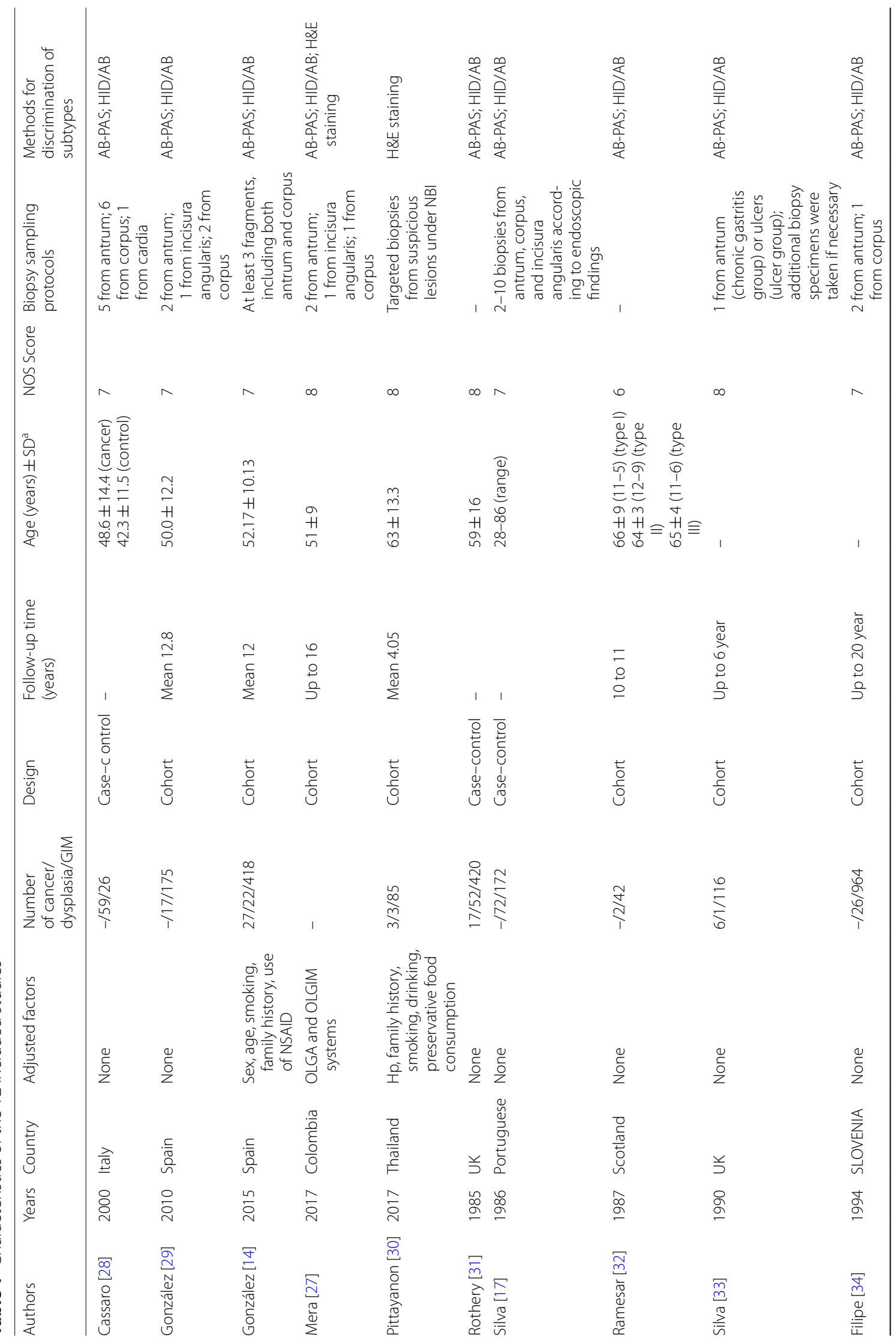




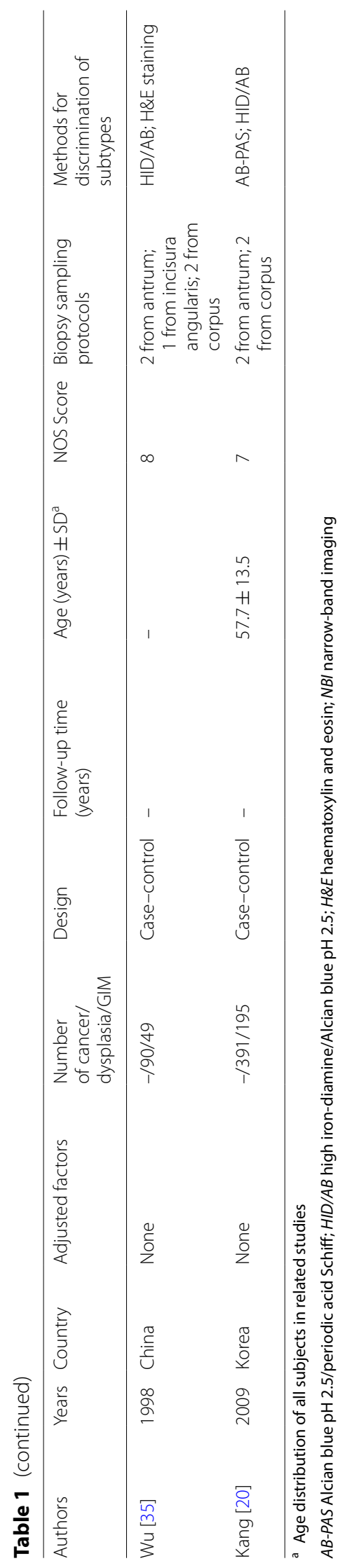




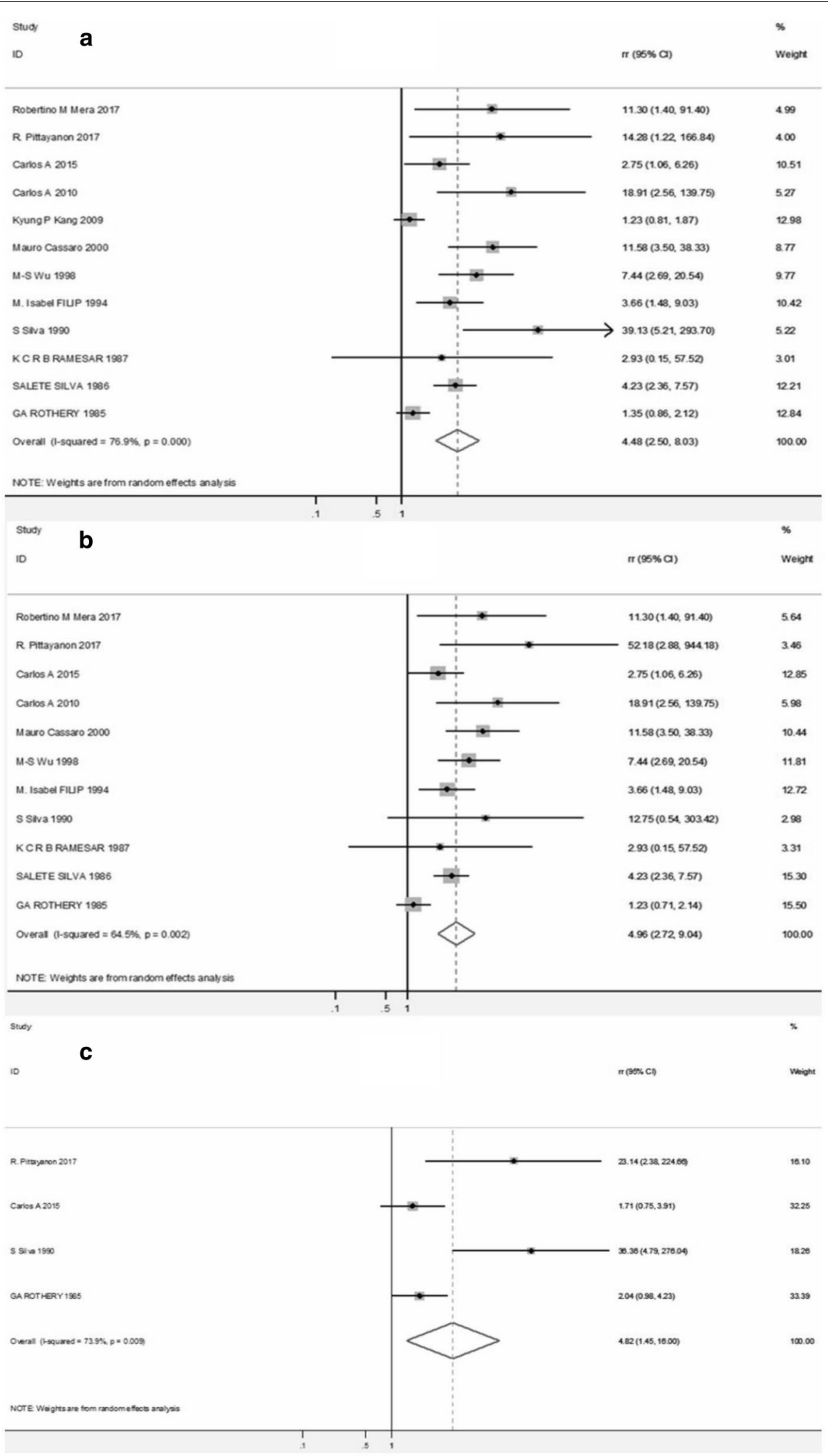

Fig. 2 Forest plots for cancer/dysplasia (a), cancer (b), dysplasia (c) risk among patients with IIM when compared with CIM 


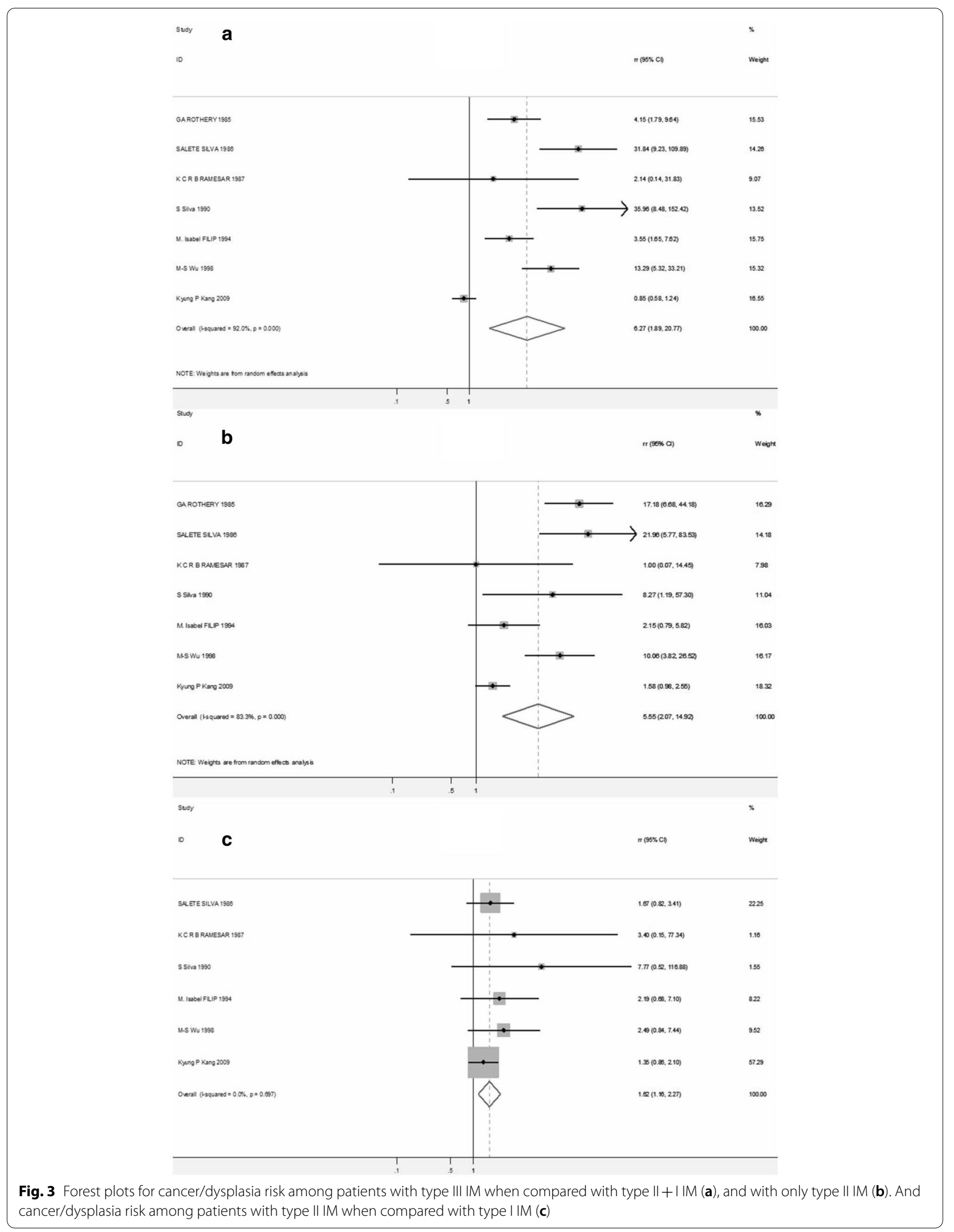


Table 2 Subgroup analyses of GIM and risk of cancer/dysplasia

\begin{tabular}{|c|c|c|c|c|}
\hline \multirow[t]{2}{*}{ Group } & \multirow[t]{2}{*}{ No. of studies } & \multirow[t]{2}{*}{ Pooled RR (95\% Cl) } & \multicolumn{2}{|c|}{ Heterogeneity } \\
\hline & & & $\overline{1^{2}(\%)}$ & $P$ \\
\hline \multicolumn{5}{|l|}{ Subtype } \\
\hline III vs. II + I & 7 & $6.27(1.89-20.77)$ & 92.0 & $<0.001$ \\
\hline ||| vs. || & 7 & $5.55(2.07-14.92)$ & 83.3 & $<0.001$ \\
\hline$\|\left. v s\right|^{a}$ & 6 & $1.62(1.16-2.27)$ & 0.0 & 0.697 \\
\hline \multicolumn{5}{|l|}{ Design } \\
\hline Cohort & 7 & $5.05(2.96-8.63)$ & 34.9 & 0.162 \\
\hline Case control & 5 & $3.15(1.48-6.73)$ & 86.3 & $<0.001$ \\
\hline \multicolumn{5}{|l|}{ Country of origin } \\
\hline East Asia & 3 & $4.01(0.82-19.61)$ & 84.9 & $<0.001$ \\
\hline Western countries & 8 & $4.65(2.30-9.42)$ & 74.8 & $<0.001$ \\
\hline
\end{tabular}

a Results of the remaining 6 studies after excluding 1 study [31] by sensitivity analysis

[pooled $\mathrm{RR}=4.65(95 \%$ CI 2.30-9.42)] but not in the East Asian population [pooled RR $=4.01(95 \%$ CI $0.82-19.61)]$. On the one hand, the number of studies included conducted in Asian countries was relatively small, and the result should be interpreted with caution. On the other hand, other than intestinal metaplasia subtypes, factors such as gene/race, preservative food consumption [34], and Helicobacter pylori infection [38] can also affect the occurrence of cancer/dysplasia. As an area of high incidence of gastric cancer, gene/race and diet may play a more important role in the malignant transformation of patients with intestinal metaplasia in East Asia which can interfere the results.

In addition to the comparison between IIM and CIM, this study also merged the risk of cancer/dysplasia of the three intestinal subtypes. The results showed that type III IM had a higher risk of cancer/dysplasia compared with type II + type I, or type II only. And type II also had a higher risk when compared with type I. Previous studies mainly underlined IIM and CIM. This study suggested that the risk of gastric cancer/dysplasia increased from type I, II, to III intestinal metaplasia. Thus, further attention should be paid on type III intestinal metaplasia in clinical practice. Correa's gastric cancer model shows a gradual process from atrophy, intestinal metaplasia, to dysplasia and cancer. Is it possible that the type I, II, and III intestinal metaplasia representing different stages of a gradually developing process of gastric lesions? Further researches are needed to answer this question.

There were several limitations in this study. First, the results of some subgroup might be less accurate for the relatively small number of studies included. Second, we failed to explain the source of heterogeneity.
Third, confounding factors were not controlled in all of the included studies. Besides, follow up time of cohort studies might affect the incidence of gastric cancer/dysplasia for patients with GIM.

\section{Conclusion}

In conclusion, patients with IIM were at higher risk for gastric cancer/dysplasia than those with CIM. The risk of progressing to cancer/dysplasia in type I, II, and III intestinal metaplasia increased gradually. The predictive value of IIM for cancer/dysplasia in East Asian population needs further discussion.

\section{Supplementary Information}

The online version contains supplementary material available at https://doi. org/10.1186/s12935-021-01869-0.

Additional file 1: Figure S1. Dysplasia/cancer risk among patients with IIM when compared with CIM: sensitivity analysis. Figure S2. Dysplasia/ cancer risk among patients with IIM when compared with CIM: Egger's publication bias plot (a), funnel plot (b), and filed funnel plot (c) after adding 5 more studies (inside the box) by trim and fill method. Figure S3. Forest plots for dysplasia/cancer risk among patients with type II IM when compared with type I IM (before sensitivity analysis). Figure S4. Dysplasia/cancer risk among patients with type II IM when compared with type I IM: sensitivity analysis. Table S1. Dysplasia/cancer risk among patients with IIM when compared with CIM: sensitivity analysis. Table S2. Dysplasia/cancer risk among patients with IIM when compared with CIM: publication bias (Egger's test). Table S3. Dysplasia/cancer risk among patients with IIM when compared with CIM: sensitivity analysis: trim and fill method. Table S4. Dysplasia/cancer risk among patients with type II IM when compared with type I IM: sensitivity analysis.

\section{Acknowledgements}

All authors have contributed significantly. All authors are in agreement with the content of the manuscript.

\section{Authors' contributions}

NW and RS conceived the idea for the review. NW and MZ and SL performed the literature search, data extraction and analysis. NW and ZZ drafted the article. All authors read and approved the final manuscript.

\section{Funding \\ None.}

\section{Availability of data and materials}

The datasets used or analyzed during the current study are available from the corresponding author on reasonable request.

\section{Declarations}

Ethics approval and consent to participate Not applicable.

\section{Consent for publication}

All authors are in agreement with the publication of the manuscript.

\section{Competing interests}

No benefits in any form have been received or will be received from a commercial party related directly or indirectly to the subject of this article. The authors declare there is no conflicts of interest regarding the publication of this paper. 


\section{Author details}

${ }_{1}^{1}$ Medical School of Southeast University, Nanjing 210009, China. ${ }^{2}$ Department of Gastroenterology, Southeast University Affiliated Zhongda Hospital, No. 87 Dingjiaqiao, Nanjing 210009, China.

Received: 16 November 2020 Accepted: 6 March 2021 Published online: 17 March 2021

\section{References}

1. Shao L, Li P, Ye J, Chen J, Han Y, Cai J, et al. Risk of gastric cancer among patients with gastric intestinal metaplasia. Int J Cancer. 2018;143(7):1671-7.

2. Eidt S, Stolte M. Prevalence of intestinal metaplasia in Helicobacter pylori gastritis. Scand J Gastroenterol. 1994;29:607-10.

3. Song H, Ekheden IG, Zheng Z, Ericsson J, Nyrén O, Ye W. Incidence of gastric cancer among patients with gastric precancerous lesions: observational cohort study in a low risk western population. BMJ. 2015:27(351):h3867.

4. De Vries AC, van Grieken NC, Looman CW, Casparie MK, de Vries E, Meijer GA, et al. Gastric cancer risk in patients with premalignant gastric lesions: a nationwide cohort study in the Netherlands. Gastroenterology. 2008:134(4):945-52.

5. Eriksson NK, Kärkkäinen PA, Färkkilä MA, Arkkila PE. Prevalence and distribution of gastric intestinal metaplasia and its subtypes. Dig Liver Dis. 2008;40(5):355-60.

6. Olmez S, Aslan M, Erten R, Sayar S, Bayram I. The prevalence of gastric intestinal metaplasia and distribution of Helicobacter pylori infection, atrophy, dysplasia, and cancer in its subtypes. Gastroenterol Res Pract. 2015:2015:434039.

7. Uemura N, Okamoto S, Yamamoto S, Matsumura N, Yamaguchi S, Yamakido M, et al. Helicobacter pylori infection and the development of gastric cancer. N Engl J Med. 2001;345(11):784-9.

8. Yue $H$, Shan L, Bin L. The significance of OLGA and OLGIM staging systems in the risk assessment of gastric cancer: a systematic review and metaanalysis. Gastric Cancer. 2018;21(4):579-87.

9. Pimentel-Nunes P, Dinis-Ribeiro M, Soares JB, Marcos-Pinto R, Santos C, Rolanda $C$, et al. A multicenter validation of an endoscopic classification with narrow band imaging for gastric precancerous and cancerous lesions. Endoscopy. 2012;44(3):236-46.

10. Pimentel-Nunes P, Libânio D, Marcos-Pinto R, Areia M, Leja M, Esposito G, et al. Management of epithelial precancerous conditions and lesions in the stomach (MAPS II): European Society of Gastrointestinal Endoscopy (ESGE), European Helicobacter and Microbiota Study Group (EHMSG), European Society of Pathology (ESP), and Sociedade Portuguesa de Endoscopia Digestiva (SPED) guideline update 2019. Endoscopy. 2019;51(4):365-88.

11. Oliveira C, Pinheiro H, Figueiredo J, Seruca R, Carneiro F. Familial gastric cancer: genetic susceptibility, pathology, and implications for management. Lancet Oncol. 2015;16(2):e60-70.

12. Zullo A, Hassan C, Romiti A, Giusto M, Guerriero C, Lorenzetti R, et al. Follow-up of intestinal metaplasia in the stomach: when, how and why. World J Gastrointest Oncol. 2012;4(3):30-6.

13. Park $\mathrm{YH}, \mathrm{Kim}$ N. Review of atrophic gastritis and intestinal metaplasia as a premalignant lesion of gastric cancer. J Cancer Prev. 2015;20(1):25-40.

14. González CA, Sanz-Anquela JM, Companioni O, Bonet C, Berdasco M, López C, et al. Incomplete type of intestinal metaplasia has the highest risk to progress to gastric cancer: results of the Spanish follow-up multicenter study. J Gastroenterol Hepatol. 2016;31(5):953-8.

15. Conchillo JM, Houben G, de Bruïne A, Stockbrügger R. Is type III intestinal metaplasia an obligatory precancerous lesion in intestinal-type gastric carcinoma? Eur J Cancer Prev. 2001;10(4):307-12.

16. Matsukura N, Onda M, Tokunaga A, Matsuda N, Yamashita K. Mucosal IgA antibody against Helicobacter pylori in chronic gastritis and intestinal metaplasia detected by the Tes-Tape method in resection specimens after gastrectomy for gastric cancer. Cancer. 1995;75(6 Suppl):1472-7.

17. Silva S, Filipe MI. Intestinal metaplasia and its variants in the gastric mucosa of Portuguese subjects: a comparative analysis of biopsy and gastrectomy material. Hum Pathol. 1986;17(10):988-95.
18. Matsukuma A, Mori M, Enjoji M. Sulphomucin-secreting intestinal metaplasia in the human gastric mucosa. An association with intestinal-type gastric carcinoma. Cancer. 1990;66(4):689-94.

19. El-Zimaity HM, Ramchatesingh J, Saeed MA, Graham DY. Gastric intestinal metaplasia: subtypes and natural history. J Clin Pathol. 2001;54(9):679-83.

20. Kang KP, Lee HS, Kim N, Kang HM, Park YS, Lee DH, et al. Role of intestinal metaplasia subtyping in the risk of gastric cancer in Korea. J Gastroenterol Hepatol. 2009;24(1):140-8.

21. Stang A. Critical evaluaion of the Newcastle-Ottawa scale for the assessment of the quality of nonrandomized stuies in meta-analysises. Eur J Epidemiol. 2010;25(9):603-5.

22. Higgins JPT, Thompson SG. Quantifying heterogeneity in a meta-analysis. Stat Med. 2002;21:1539-58.

23. Thomas JS. Nonparametric trim and fill analysis of publication bias in meta-analysis. Stata Tech Bull. 2001;57:8-14.

24. Duval S, Tweedie R. Trim and fill: a simple funnel-plot-based method of testing and adjusting for publication bias in meta-analysis. Biometrics. 2000;56(2):455-63.

25. Zhang J, Yu KF. What's the relative risk? A method of correcting the odds ratio in cohort studies of common outcomes. JAMA. 1998;280:1690-1.

26. Spruance SL, Reid JE, Grace M, Samore M. Hazard ratio in clinical trials. Antimicrob Agents Chemother. 2004;48(8):2787-92.

27. Mera RM, Bravo LE, Camargo MC, Bravo JC, Delgado AG, Romero-Gallo J, et al. Dynamics of Helicobacter pylori infection as a determinant of progression of gastric precancerous lesions: 16-year follow-up of an eradication trial. Gut. 2018;67(7):1239-46.

28. Cassaro M, Rugge M, Gutierrez O, Leandro G, Graham DY, Genta RM. Topographic patterns of intestinal metaplasia and gastric cancer. Am J Gastroenterol. 2000;95(6):1431-8.

29. González CA, Pardo ML, Liso JM, Alonso P, Bonet C, Garcia RM, et al. Gastric cancer occurrence in preneoplastic lesions: a long-term follow-up in a high-risk area in Spain. Int J Cancer. 2010;127(11):2654-60.

30. Pittayanon R, Rerknimitr R, Klaikaew N, Sanpavat A, Chaithongrat S, Mahachai $\mathrm{V}$, et al. The risk of gastric cancer in patients with gastric intestinal metaplasia in 5-year follow-up. Aliment Pharmacol Ther. 2017;46(1):40-5.

31. Rothery GA, Day DW. Intestinal metaplasia in endoscopic biopsy specimens of gastric mucosa. J Clin Pathol. 1985;38(6):613-21.

32. Ramesar KC, Sanders DS, Hopwood D. Limited value of type III intestinal metaplasia in predicting risk of gastric carcinoma. J Clin Pathol. 1987;40(11):1287-90.

33. Silva S, Filipe MI, Pinho A. Variants of intestinal metaplasia in the evolution of chronic atrophic gastritis and gastric ulcer. A follow up study. Gut. 1990;31(10):1097-104.

34. Filipe MI, Muñoz N, Matko I, Kato I, Pompe-Kirn V, Jutersek A, et al. Intestinal metaplasia types and the risk of gastric cancer: a cohort study in Slovenia. Int J Cancer. 1994;57(3):324-9.

35. Wu MS, Shun CT, Lee WC, Chen CJ, Wang HP, Lee WJ, et al. Gastric cancer risk in relation to Helicobacter pylori infection and subtypes of intestinal metaplasia. Br J Cancer. 1998;78(1):125-8.

36. Banks M, Graham D, Jansen M, Gotoda T, Coda S, di Pietro M, et al. British Society of Gastroenterology guidelines on the diagnosis and management of patients at risk of gastric adenocarcinoma Study Group (EHMSG), European Society of Pathology (ESP), and Sociedade Portuguesa de Endoscopia Digestiva (SPED) guideline update 2019. Gut. 2019;68:1545-75

37. Craanen ME, Blok P, Dekker W, Ferwerda J, Tytgat GN. Prevalence of subtypes of intestinal metaplasia in gastric antral mucosa. Dig Dis Sci. 1991;36(11):1529-36

38. Capitani N, Codolo G, Vallese F, Minervini G, Grassi A, Cianchi F, et al. The lipoprotein HP1454 of Helicobacter pylori regulates T-cell response by shaping T-cell receptor signalling. Cell Microbiol. 2019;21(5):e13006.

\section{Publisher's Note}

Springer Nature remains neutral with regard to jurisdictional claims in published maps and institutional affiliations. 